\title{
Effectiveness of a new standardised Urinary Continence Physiotherapy Programme for community-dwelling older women in Hong Kong
}

\author{
BS Leong, Nicola W Mok*
}

\section{A B S T R A C T}

Objective: To examine the effectiveness of a standardised Urinary Continence Physiotherapy Programme for older Chinese women with stress, urge, or mixed urinary incontinence.

Design: A controlled trial.

Setting: Six elderly community health centres in Hong Kong.

Participants: A total of 55 women aged over 65 years with mild-to-moderate urinary incontinence.

Interventions: Participants were randomly assigned to the intervention group $(n=27)$ where they received eight sessions of Urinary Continence Physiotherapy Programme for 12 weeks. This group received education about urinary incontinence, pelvic floor muscle training with manual palpation and verbal feedback, and behavioural therapy. The control group $(n=28)$ was given advice and an educational pamphlet on urinary incontinence.

Results: There was significant improvement in urinary symptoms in the intervention group, especially in the first 5 weeks. Compared with the control group, participants receiving the intervention showed significant reduction in urinary incontinence episodes per week with a mean difference of -6.4 (95\% confidence interval, -8.9 to -3.9; $t=-5.3 ; \mathrm{P}<0.001)$ and significant improvement of quality of life with a mean difference of $-3.93(95 \%$ measured by Incontinence Impact Questionnaire Short Form modified Chinese (Taiwan) version. The subjective perception of improvement, measured by an 11-point visual analogue scale, was markedly better in the intervention group (mean, 8.7; standard deviation, 1.0; 95\% confidence interval, 8.3-9.1) than in the control group (mean, 1.4; standard deviation, $0.7 ; 95 \%$ confidence interval, 1.2-1.7; $t=33.9$; $\mathrm{P}<0.001)$. The mean treatment satisfaction in the intervention group was 9.5 (standard deviation, 0.8) as measured by an 11-point visual analogue scale.

Conclusions: This study demonstrated that the Urinary Continence Physiotherapy Programme was effective in alleviating urinary symptoms among older Chinese women with mild-to-moderate heterogeneous urinary incontinence.

Hong Kong Med J 2015;21:30-7

DOI: $10.12809 / \mathrm{hkmj} 134185$

1,2 BS Leong, MSc, BSCPT

${ }^{1}$ NW Mok *, PhD

Department of Rehabilitation Sciences, Hong Kong Polytechnic University, Hunghom, Hong Kong

Elderly Health Service, Department of Health, Hong Kong

* Corresponding author: nicola.mok@polyu.edu.hk

New knowledge added by this study

- This standardised Urinary Continence Physiotherapy Programme is effective in improving various types of urinary incontinence of mild-to-moderate severity.

- The superior exercise compliance and treatment outcome in this study are likely attributed to the palpation and verbal feedback provided by physiotherapists during pelvic floor muscle training.

Implications for clinical practice or policy

A standardised urinary continence programme consisting of education, supervised pelvic floor muscle training with palpation, and behavioural therapy is an effective first-line management for various types of urinary incontinence in a community setting.

\section{Introduction}

Urinary incontinence (UI), defined as "the complaint of any involuntary leakage of urine", ${ }^{\text {is }}$ a major clinical problem, and a significant cause of disability and dependency in the aged population. It is a condition with heterogeneous pathology and commonly classified as stress urinary incontinence (SUI), urge urinary incontinence (UUI), and mixed urinary incontinence (MUI) depending on the symptom behaviour. While the prevalence of UI in older women, globally, is estimated to range from $15 \%$ to $30 \%,{ }^{2}$ the reported prevalence rate of UI in 
Hong Kong ranges from 20\% to $52 \% .^{3}$ It has been acknowledged that UI is associated with profound adverse impact on the quality of life (QoL) of the sufferers. ${ }^{3,4}$ The impact of UI is so substantial that community-dwelling elderly with UI reported inferior physical and mental health, worse selfperceived health status, greater disability, and more depressive symptoms. ${ }^{5}$ In addition, the extent of the impact was shown to be associated with the severity of UI. Therefore, it is important to investigate a safe and effective treatment strategy in this population, especially in a community setting.

Conservative management has been recommended as the first-line management for UI. It is acknowledged that a variety of conservative management strategies which require patient's active participation shows promising results for patients with UI. These include pelvic floor muscle training (PFMT), ${ }^{6,7}$ vaginal cones, ${ }^{8}$ bladder training (BT), ${ }^{9}$ and even combination of PFMT and general lumbopelvic mobilisation exercises. ${ }^{10}$ A recent Cochrane review ${ }^{7}$ suggested that PFMT, the 'knack' manoeuvre (a voluntary counterbracing type of contraction during physical stress), and BT are effective strategies in the management of UI in general. In particular, a combination of PFMT and BT was shown to have superior outcome than BT alone for the management of UUI and MUI. ${ }^{9}$ However, to date, there is insufficient conclusive evidence on the best approach for PFMT. ${ }^{11}$ In addition, the applicability and effectiveness of PFMT and BT for treating UI have not been properly evaluated in the elderly Chinese population, especially in randomised controlled studies. The aim of this study was to evaluate the effectiveness of a Urinary Continence Physiotherapy Programme (UCPP), which is a comprehensive programme involving education and exercise (PFMT and BT) components for managing SUI, UUI, and MUI in older Chinese women in a community setting.

\section{Methods}

A total of 60 subjects were recruited for screening by convenience sampling from six Elderly Health Centres (EHCs), Department of Health, Hong Kong. Inclusion criteria were Chinese females aged 65 years or older who had a clinical diagnosis of SUI, UUI, or MUI (with reference to the definition from International Continence Society ${ }^{1}$ ) of a mild-tomoderate severity (based on the scoring system by Lagro-Janssen et $\mathrm{al}^{12}$ ) which is made by the EHC medical officers in-charge. Exclusion criteria were active urinary tract infection, patients on diuretic medication, presence of bladder pathology or dysfunction due to genitourinary fistula, tumour, pelvic irradiation, neurological or other chronic conditions (eg diabetes mellitus, Parkinson's disease), previous anti-incontinence surgery, significant

\section{為小便失禁的香港社區年長婦女設計的 「邁向清爽」計劃的成效 梁碧茜、莫慧娟}

目的：探討為患有壓力性、急切性或混合性小便失禁的年長婦女設計 的「邁向清爽」計劃的效用。

設計：對照試驗。

安排：香港六間長者社區健康中心。

參與者：患有輕微至中等小便失禁的55名65歲或以上年長婦女。

介入治療：患者被隨機分配到治療組 (27例) 參與 12 週共 8 節的 $「$ 邁 向清爽」課堂。她們均接受有關尿失禁的教育、盆底肌肉訓練並配以 觸診和意見反映, 以及行為治療。對照組則獲派和講解有關小便失禁 的教育單張。

結果：治療期內尤其在首 5 週時, 治療組的尿道症狀有明顯改善。與 對照組比較, 治療組七天的小便失禁次數明顯減少, 平均差幅為-6.4 （ 95\%置信區間：-8.9至-3.9； $t=-5.3 ； \mathrm{P}<0.001 ） ；$ 而小便失禁影 響問卷簡表中文 (台灣) 改良版的評估顯示治療組有較佳生活質素 的提升, 平均差幅為-3.93（95\%置信區間： -5.08 至-2.78； $t=-6.9$; $\mathrm{P}<0.001)$ ）以 11 點視覺模擬評分作評估, 治療組的自覺改善程度 較對照組好；前者為平均 8.7 分，標準差 $1.0 ； 95 \%$ 置信區間：8.4至 9.1 ; 後者的相應值為 1.4 分, $0.7 ； 1.2-1.7 （ t=33.9 ； \mathrm{P}<0.001)$ 按 11 點視覺模擬評分作評估, 治療組對計劃的滿意程度平均為9.5分 (標準差0.8)。

結論：本研究顯示對於患有輕微至中等壓力性、急切性或混合性小便 失禁的年長婦女, 「邁向清爽」計劃有助舒緩其尿道症狀。

cognitive impairment assessed by the Cantonese version of Mini-Mental State Examination Score (CMMSE ${ }^{13}$ with cutoffs of: $\leq 18$ for illiterate subjects, $\leq 20$ for those who had had 1 to 2 years of schooling, $\leq 22$ for those who had had more than 2 years of schooling out of a maximum score of 30), obesity (body mass index [BMI] of $>30 \mathrm{~kg} / \mathrm{m}^{2}$ ), and use of concomitant treatments during the trial.

Randomisation was performed prior to the study by an off-site investigator using a computerised randomisation programme with allocation concealment by sequentially numbered, opaque, and sealed envelopes. After taking consent, grouping of the individual participants was revealed to the principal investigator by phone. Overall, 55 eligible participants were assigned to the intervention $(n=27)$ or control $(n=28)$ groups. The trial period lasted for 12 weeks. The study was approved by the Institutional Medical Research Ethics Committee and was conducted in accordance with the Declaration of Helsinki. ${ }^{14}$

\section{Intervention protocol}

One physiotherapist was responsible for delivering 
assessment and treatment to all subjects during the trial period of 12 weeks, and she was not blinded to the intervention.

The intervention group received a 30-minute individual training session at a pre-decided time of the day, once weekly for the first 4 weeks; and then once bi-weekly for the remaining 8 weeks. A total of eight treatment sessions were given to each recipient. There were three major components in the UCPP: education (anatomy of the pelvic floor muscle $[\mathrm{PFM}]$ and urinary tract, urinary continence mechanism, and bladder care), PFMT with the aid of vaginal palpation, and BT. Pelvic floor muscle training included Kegel exercise programme and neuromuscular re-education (the 'knack'). ${ }^{15}$ Bladder training involved strategies to increase the time interval between voids by a combination of progressive void schedules, urge suppression, distraction, self-monitoring, and reinforcement.

Four stages of Kegel's PFMT programme were adopted in this study, including (1) muscle awareness, (2) strengthening, (3) endurance, and (4) habit building and muscle utilisation. ${ }^{16}$ The exercise regimen was designed to progressively strengthen both type I and type II muscle fibres of the pelvic floor. In the first 2 weeks (muscle awareness phase), one set of 10 (week 1) and 15 (week 2) slow submaximal contractions for 5 seconds each and five fast maximal contractions with a 10 -second relaxation between contractions was performed in lying down position. In the strengthening phase (weeks 3 to 4), the muscle-strengthening element was reinforced by gradually increasing the number of submaximal contractions to 25 per session with an increment of five repetitions per week in gravity-dependent position including sitting and standing. The number of fast maximal contractions (5) remained the same as in the awareness phase. In the endurance phase (weeks 5 to 8 ), the training was more focused on improving the performance of slow and sustained contractions of PFMs by increasing the contraction time to 10 seconds with submaximal contraction while keeping the exercise position and number of both submaximal and maximal contractions as in week 4 . In the habit-building and muscle utilisation phase (weeks 9 to 12), the learnt neuromuscular re-education technique (the 'knack') and urge suppression strategies were reinforced. In this period, one set of 30 slow submaximal contractions for 10 seconds each and 10 fast maximal contractions with a 10-second relaxation between contractions was practised. Participants were asked to perform three sets of the above-mentioned exercise at specific periods as part of the home programme.

The control group was given advice and received an educational pamphlet with information about management of UI at baseline. Participants were given an appointment for a follow-up visit in 12 weeks.

\section{Outcome measures}

A number of indicators were employed to assess different aspects of outcomes. First, the number of UI episodes in the previous 7 days (UI7) was examined using a weekly bladder diary log sheet, which was also the primary outcome measure of this study. Information for UI7 was collected at baseline and then weekly until the end of the programme (12 weeks). Second, a validated condition-specific QoL assessment tool-Incontinence Impact Questionnaire Short Form (IIQ-7) Chinese (Taiwan) version ${ }^{17}$ - was used to study the impact of UI on QoL and its change with the intervention after minor modifications were made to align with the local culture. Content validation was made by a panel of doctors who reviewed the instrument and determined if the questions satisfied the content domain. Seven items were included in the questionnaire to examine if the subjects were suffering from urine leakage under those specific situations. The questionnaire was administered by the same physiotherapist and the subjects were asked to choose the most appropriate response to those 7 items on a 4-point ordinal scale, with 0 meaning "not at all affected", 1 "slightly affected", 2 "moderately affected", and 3 "greatly affected". The maximum score of 21 indicated a great impact of UI on QoL. Third, subjective perception of improvement was assessed with a $10-\mathrm{cm}$ visual analogue scale (VAS) rated from 0 to 10 , with 0 suggesting "no improvement" and 10 "complete relief" at the end of the intervention period. Fourth, another VAS was used to assess subjects' satisfaction to treatment (on a 0 to 10 rating), with 0 being "totally dissatisfied" and 10 "totally satisfied". The IIQ-7 was collected at baseline and at the end of the programme. Compliance with treatment in the intervention group was evaluated from two perspectives: attendance and compliance with home exercises. Attendance was reviewed by calculating the proportion of sessions that were attended by an individual. Compliance with home exercises was also reviewed by calculating the reported frequency of exercises being executed. Any drawbacks and adverse effects during the intervention period were also monitored.

\section{Statistical analysis}

The sample size calculation based on the power estimation and results of a similar study, ${ }^{18}$ with a power of 0.8 and $\alpha=0.05$ and an attrition rate of $30 \%$, revealed that a recruitment sample of 60 participants (30 participants in each group) was required. Statistical analysis was performed with the Statistical Package for the Social Sciences (Windows version 13.0; SPSS Inc, Chicago [IL], US). Any missing data were treated with "the last observation carried forward" approach. Independent $t$ tests (for 
parametric data) or Mann-Whitney test (for nonparametric or non-normally distributed data) and Chi squared tests (for nominal/ordinal data) were used to compare the demographic data and outcome variables between the intervention and control groups at baseline. Pairwise comparisons with the $\mathrm{P}$ value adjusted using Bonferroni correction was used to examine for the differences in UI7 between week 1 and the subsequent time points during the intervention period (eg between week 1 and 2, week 1 and 3, etc). The results were presented as mean (standard deviation [SD]).

\section{Results}

The demographics and baseline measurements for the participants are shown in Table 1. Of the 60 participants recruited for screening, three did not turn up for assessment, one declined to participate in the study, and one was excluded due to impaired mental status (Fig 1). The majority of the participants were in their 70 s with a mean $( \pm$ SD) age of 74.3 \pm 4.6 years. There was no significant difference between the groups in terms of age, BMI, parity, education level, mental status (CMMSE), and the characteristics of UI at baseline.

\section{Number of urinary incontinence episodes in 7 days}

There was a significant interaction between time and groups in UI7 $\left(\mathrm{F}_{(1,53)}=33.14 ; \mathrm{P}<0.001\right)$. A significant reduction in UI7 was noted only in the intervention group. There was significant difference between the control and intervention groups $(t=-5.3 ; \mathrm{P}<0.001)$ at 12 weeks with a mean difference of $-6.4(95 \%$ confidence interval $[\mathrm{CI}],-8.9$ to -3.9$)$. The mean numbers of UI7 for intervention and control groups were $1.0 \pm 1.9(95 \% \mathrm{CI}, 0.3-1.7)$ and $7.4 \pm 6.2(95 \%$ CI, 5.0-9.8), respectively, at 12 weeks (Table 2). When comparing the percentage reduction ([pretreatment frequency - post-treatment frequency] / [pre-treatment frequency] $x$ 100\%) in UI7, the intervention group demonstrated a mean of more

TABLE I. Characteristics of subjects at baseline*

\begin{tabular}{|c|c|c|c|c|}
\hline Characteristic & Overall $(n=55)$ & Intervention group $(\mathrm{n}=27)$ & Control group $(n=28)$ & P value \\
\hline Age (years) & $74.3 \pm 4.6$ & $73.0 \pm 4.0$ & $75.4 \pm 5.0$ & 0.06 \\
\hline BMI $\left(\mathrm{kg} / \mathrm{m}^{2}\right)$ & $25.2 \pm 2.6$ & $24.9 \pm 2.7$ & $25.4 \pm 2.6$ & 0.42 \\
\hline Parity† & $4.3 \pm 2.1$ & $4.1 \pm 1.6$ & $4.5 \pm 2.4$ & 0.44 \\
\hline Education level & & & & 0.26 \\
\hline Illiterate & $24(43.6)$ & $8(29.6)$ & $16(57.1)$ & \\
\hline Below primary school & $13(23.6)$ & $10(37.0)$ & $3(10.7)$ & \\
\hline Primary school & $10(18.2)$ & $6(22.2)$ & $4(14.3)$ & \\
\hline Secondary school or above & $8(14.5)$ & $3(11.1)$ & $5(17.9)$ & \\
\hline CMMSE score & $27.6 \pm 2.1$ & $28.0 \pm 2.0$ & $27.3 \pm 2.1$ & 0.22 \\
\hline Duration of incontinence & & & & 0.36 \\
\hline$<2$ Years & $33(60.0)$ & $15(55.6)$ & $18(64.3)$ & \\
\hline 2-5 Years & $17(30.9)$ & $8(29.6)$ & $9(32.1)$ & \\
\hline$>5$ Years & $5(9.1)$ & $4(14.8)$ & $1(3.6)$ & \\
\hline Type of incontinence & & & & 0.59 \\
\hline SUI & $28(50.9)$ & $13(48.1)$ & $15(53.6)$ & \\
\hline UUI & $9(16.4)$ & $4(14.8)$ & $5(17.9)$ & \\
\hline MUI & $18(32.7)$ & $10(37.0)$ & $8(28.6)$ & \\
\hline Severity of incontinence & & & & 0.22 \\
\hline Mild & $25(45.5)$ & $10(37.0)$ & $15(53.6)$ & \\
\hline Moderate & $30(54.5)$ & $17(63.0)$ & $13(46.4)$ & \\
\hline UI7 & $9.4 \pm 7.8$ & $11.0 \pm 9.3$ & $8.0 \pm 6.3$ & 0.17 \\
\hline IIQ-7 (Chinese version) score & $6.5 \pm 4.0$ & $7.6 \pm 4.6$ & $5.5 \pm 3.0$ & 0.06 \\
\hline
\end{tabular}

Abbreviations: BMI = body mass index; CMMSE = Cantonese version of Mini-Mental State Examination; $\| \mathrm{Q}-7=$ Incontinence Impact Questionnaire (Short Form); MUI = mixed urinary incontinence; SUI = stress urinary incontinence; UI7 = No. of urinary incontinence episodes in the last 7 days; UUI = urge urinary incontinence

* Data are shown as mean \pm standard deviation, or No. (\%)

+ Parity $=$ No. of previous parity

₹ Statistical tests to detect between-group differences were independent $t$ test for age, BMI, parity, CMMSE, duration of incontinence, UI7, and IIQ-7; and Chi squared test for education level, types of incontinence, and incontinence severity 


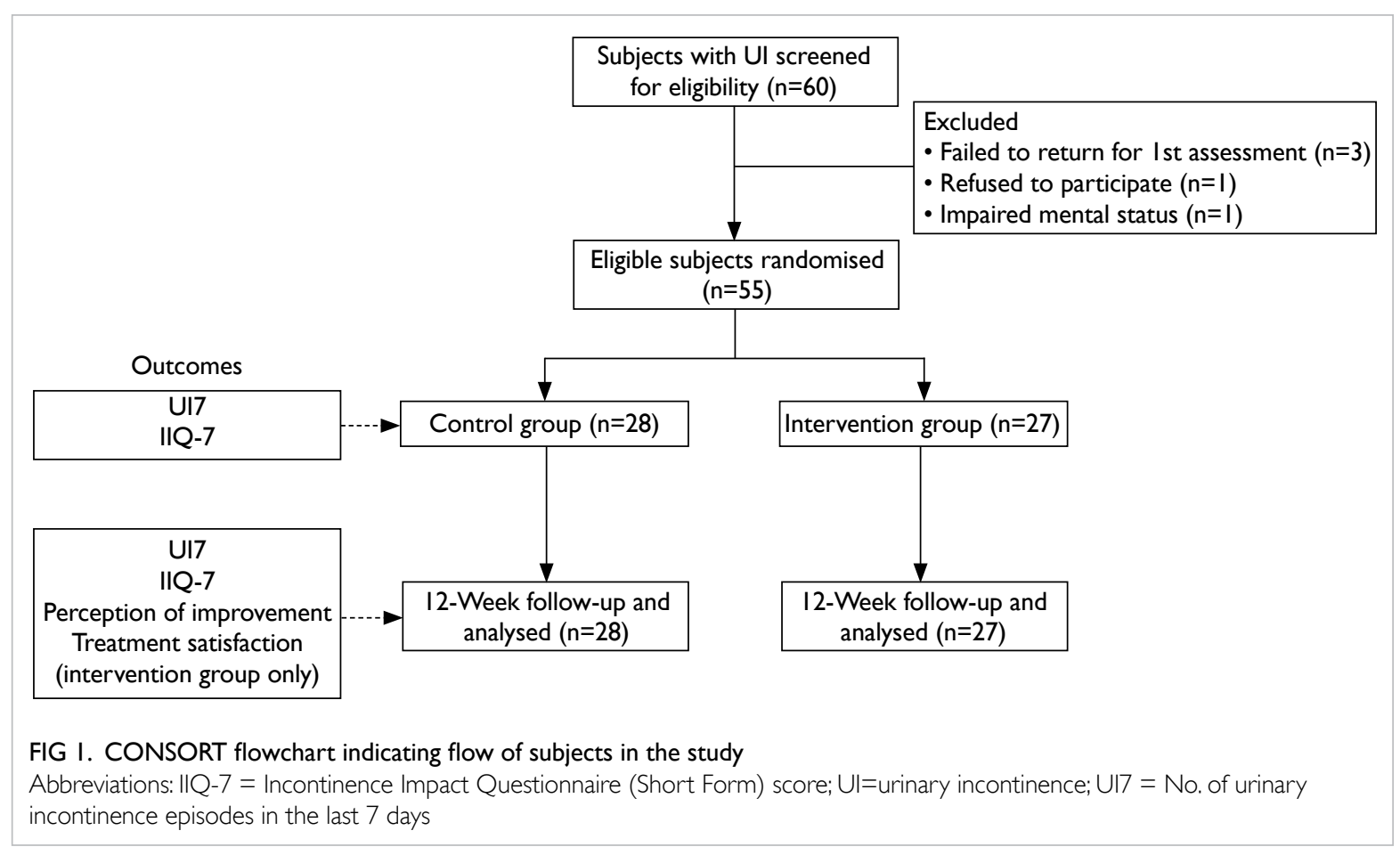

TABLE 2. Results of outcome measures in the two groups before and after treatment

\begin{tabular}{|c|c|c|c|c|c|}
\hline & \multicolumn{4}{|c|}{ Mean \pm standard deviation } & \multirow[t]{3}{*}{ P value* } \\
\hline & \multicolumn{2}{|c|}{ Intervention group $(n=27)$} & \multicolumn{2}{|c|}{ Control group $(n=28)$} & \\
\hline & Baseline & After 12 weeks & Baseline & After 12 weeks & \\
\hline UI7 & $11.0 \pm 6.3$ & $1.0 \pm 1.9$ & $8.0 \pm 6.3$ & $7.4 \pm 6.2$ & $<0.001 \dagger \ddagger$ \\
\hline IIQ-7 (Chinese version) score & $7.6 \pm 4.7$ & $1.1 \pm 1.2$ & $5.5 \pm 3.0$ & $5.0 \pm 2.8$ & $<0.001 \dagger \ddagger$ \\
\hline Perception of improvement (VAS 0-10) & N/A & $8.7 \pm 1.0$ & N/A & $1.4 \pm 0.7$ & $<0.001 \ddagger$ \\
\hline Treatment satisfaction (VAS $0-10$ ) & N/A & $9.5 \pm 0.8$ & N/A & N/A & - \\
\hline
\end{tabular}

Abbreviations: IIQ-7 = Incontinence Impact Questionnaire (Short Form); N/A = not applicable; UI7 = No. of urinary incontinence episodes in the last 7 days; VAS = visual analogue scale

* Statistical tests to detect differences were paired $t$ test for within-group difference between baseline and week 12 in UI7 and IIQ-7; independent $t$ test for between-group difference in perception of improvement and treatment satisfaction at week 12

+ Between baseline and week 12 in the intervention group

$\neq$ Between control and intervention groups at week 12

than $90 \%$ reduction versus $7.2 \%$ in the control group. A similar trend of improvement was shown in subjects with SUI, UUI, and MUI; however, statistical analysis was not performed due to insufficient power (Fig 2). Post-hoc pairwise comparisons (a total of 11) suggested a significant improvement from week 1 to week 5 and onwards $(\mathrm{P}<0.001)$ in the intervention group.

\section{Incontinence Impact Questionnaire Short Form modified Chinese (Taiwan) version}

A significant interaction between time and groups was noted $\left(\mathrm{F}_{(1,53)}=54.56 ; \mathrm{P}<0.001\right)$. As IIQ-7 was non-normally distributed, Mann-Whitney test was used and revealed a significant reduction of IIQ-7 (ie improvement in QoL) only in the intervention group $(t=-6.9 ; \mathrm{P}<0.001)$, with a mean difference of -3.9 $(95 \%$ CI, -5.1 to -2.8$)$ at 12 weeks (Table 2).

\section{Perception of improvement, treatment satisfaction, attendance, exercise compliance, and attrition rate}

The results of the subjective perception of improvement and level of satisfaction with treatment after 12 weeks are shown in Table 2. The majority of the participants in the intervention group were 
satisfied with the interventions and perceived a subjective improvement. The mean attendance and exercise compliance rates in the intervention group were $97.7 \% \pm 5.0 \%$ and $99.4 \% \pm 1.9 \%$, respectively. The attrition rate was zero in both groups during the whole study period. No adverse effect or discomfort was reported during the intervention period.

\section{Discussion}

In line with results from previous studies, this study further confirms that PFMT is an effective and safe treatment for women suffering from various types of UI. However, we observed a mean of $>90 \%$ reduction in UI episodes which is noticeably higher than that reported in previous similar studies $(32 \%$ to $73 \%$ reduction). ${ }^{18,19}$ Although recommendation of PFMT for women with UI is strongly supported by previous research findings, ${ }^{7}$ the best approach of PFMT programme continues to remain unclear. ${ }^{11}$ One possible explanation for the superior outcome in this study might be the combination of a few effective features in this programme, including programme duration of 12 weeks with gradual exercise progression, combination of PFMT and BT, manual vaginal palpation, and one-on-one supervised training session. First, the design of this UCPP incorporated some important concepts of exercise therapy. The training period of this study was 12 weeks, which could optimise the effect of the neural adaptation (recruitment of efficient motor units and frequency of excitation) and muscle hypertrophy according to the recommendations made by the American College of Sports Medicine. ${ }^{20}$ In addition, a recent systematic review ${ }^{7}$ also revealed that implementation of PFMT programme for at least 3 months (ie around 12 weeks) is more likely to result in greater treatment effect versus that lasting for $<12$ weeks. This programme also adopted the concepts raised by Kegel $^{16}$ in which the progression of the exercise regimen is designed according to different stages, namely muscle awareness, strengthening, endurance, habit building, and muscle utilisation. Previous studies suggested a negative correlation between increased PFM strength and UI symptoms. ${ }^{21,22}$ The improvement of UI7 at the end of the UCPP might be a direct result of the muscle training programme, although PFM strength was not measured in this study. Theoretically, skeletal muscle strengthening should be facilitated by using additional resistance ${ }^{20}$ and, therefore, it is questionable whether muscle strength could be increased by UCPP using only maximal voluntary contractions. However, a previous study has indicated muscle strength improvement with daily practice of voluntary PFM contraction without resistance, ${ }^{20}$ and absence of extra improvement in UI patient groups with intravaginal resistance as compared with the group without resistance..$^{23}$

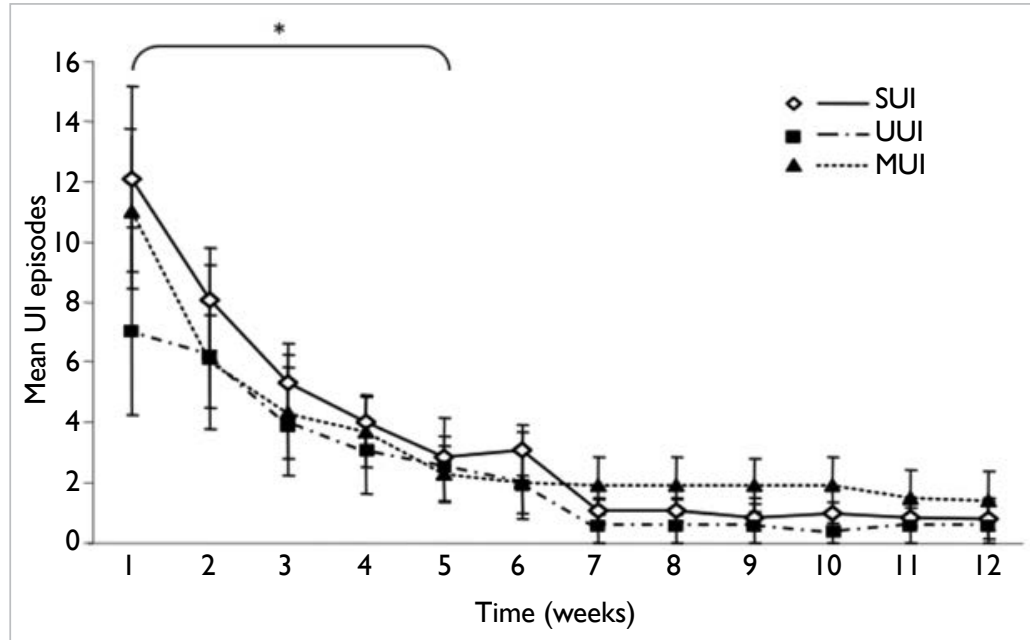

FIG 2. Progress of urinary incontinence episodes in the previous 7 days in subjects in the intervention group with various types of incontinence

The trend is similar among different types of Ul; between-group difference was not analysed due to insufficient power. Post-hoc pairwise comparisons suggested a significant improvement between week I and week $5(* \mathrm{P}<0.00 \mathrm{I})$ and onwards in the intervention group as a whole. The I bars denote standard deviations Abbreviations: $\mathrm{MUI}=$ mixed urinary incontinence; $\mathrm{SUI}=$ stress urinary incontinence; $\mathrm{UI}=$ urinary incontinence; $\mathrm{UUI}=$ urge urinary incontinence

Second, a combination of PFMT and BT was used in this UCPP. Although PFMT has been recommended as first-line management, even for women with UUI and MUI, ${ }^{7}$ there is some evidence suggesting superior outcome with combined PFMT and BT in this population. ${ }^{9}$ The result of this study confirmed these suggestions as a similar pattern of improvement was observed across the three groups (UUI, SUI, and MUI), although statistical analysis of the difference between subgroups was not performed due to the small sample size.

Third, vaginal palpation was used to facilitate and ensure correct PFM contraction. It was reported that approximately $30 \%$ of women are unable to perform isolated pelvic floor contractions with only written or verbal instructions. ${ }^{21}$ We consider the extra proprioceptive cue and specific verbal feedback are an integral part of the PFMT, and consider these to play a crucial role, especially in the initial (muscle awareness) stage. Ensuring feedback may also increase exercise adherence and compliance, apart from improving the treatment outcomes.

Fourth, the exercise sessions were conducted on a one-on-one basis for 30 minutes each. It has been reported that the amount of contact with health care professionals is positively correlated with reported cure and improvement (eg perception of change and incontinence-specific QoL) in patients with UI. ${ }^{11}$ It is argued that women receiving more attention may overestimate their improvement to please the 
treatment provider (ie experimenter effect), ${ }^{11}$ and it is strongly suggested to include more 'objective' data such as leakage episode outcomes in all PFMT trials. The result of this study revealed improvement in UI7 as well as other subjective measures (IIQ-7, perception of improvement, and treatment satisfaction), which could be considered as additional evidence base. ${ }^{11}$

The subjects' compliance with the treatment programme was excellent, as reflected by the high compliance rate with exercise regimens, high attendance rate, and zero dropouts; the dropout rates reported in previous studies were relatively high, ranging from $12 \%$ to $41 \% .^{6,18,24}$ A possible explanation for such good compliance might be the significant improvement in the early stage of the protocol, which in turn increased the participants' motivation for and confidence in adhering with the PFMT programme. Regular meetings (weekly or bi-weekly) with the same physiotherapist, who offered continuity of care, could be another possible explanation for the favourable compliance.

\section{Study limitations}

The main limitations in this study were: (1) potential selection bias due to use of convenience sampling, (2) absence of assessor blinding, (3) possibility of over-reporting, and (4) the use of the modified IIQ-7 Chinese (Taiwan) version. It has been acknowledged that convenient sampling might not be representative of the whole population suffering from UI. On the other hand, our subject group might have similar care-seeking behaviour as the client group in clinical practice. Although statistically insignificant, the data showed a small difference in some aspects of the demographic characteristics. In general, the control group tended to be slightly older ( 75.4 years vs 73.0 years), more likely to be illiterate, and have milder severity, and shorter duration of UI versus the intervention group. As these slight differences in the demographics might induce confounding, their effects warrant further investigation. Nevertheless, interpretation of the results of this study deserves some caution. In this study, five participants recruited for screening did not join the programme due to various reasons (one denied, three failed to turn up, and one due to impaired mental status). Although the specific reason for the absence of three participants was not investigated, the possibility of self-selection bias should be considered. In addition, all involved parties (the assessor, treatment provider, and the participants) were not blinded to the intervention, as opposed to the ideal experimental setup. However, it is widely acknowledged that given the nature of the treatment programme, it is difficult and often impossible to blind the treatment provider and participants during treatment. ${ }^{11}$ Due to resource limitation, it was not possible to include an independent, blinded assessor for outcome assessment. We were well aware of the possible 'experimenter effect', and therefore used UI7 as our primary outcome measure which is considered a more objective measure to minimise the possible effect of over-reporting of subjective improvement, ${ }^{11}$ although its 'objectivity' remains controversial. In addition, a significant proportion of participants (approximately 44\%) required assistance for completing the outcome questionnaires due to illiteracy. This could possibly lead to over-reporting of improvement. Furthermore, the possibility of over-reporting of compliance by participants using self-reported weekly exercise diary should not be overlooked. There is, however, no better measure available to monitor the performance of this type of exercise accurately. A recent randomised controlled trial $^{25}$ reported that severity of SUI symptoms at baseline and extent of PFM strength improvement, rather than exercise adherence, were correlated with symptom reduction for women with SUI. The result suggested a complex interaction between subject's health condition, exercise compliance and treatment effectiveness, which warrant further investigation. Therefore, we intended not to account the improvement observed in our intervention group to the high self-reported compliance rate. Finally, a modified Chinese (Taiwan) version of IIQ-7 was used in this study. We are aware of the fact that this version has not been properly validated. However, we do not believe this affects our results as the modification was minor and the version was highly comparable with the Hong Kong version which was validated subsequent to the current study.

This study examined the immediate effectiveness of the verbally instructed UCPP just after cessation of supervised training. No follow-up data were collected. It is recommended that the longterm effectiveness of UCPP be explored, especially in the light of fairly extensive literature which reported poor long-term adherence and relapse at 3 to 5 years following pelvic floor rehabilitation programme. ${ }^{26}$

\section{Conclusions}

This study demonstrated that a structured 12-week programme of PFMT with gradual exercise progression, BT with urgency suppression, and enhanced education is likely to improve episodes of urinary leakage and QoL in older Chinese women with various kinds of UI in a community setting.

\section{References}

1. Abrams P, Cardozo L, Fall M, et al. The standardisation of terminology of lower urinary tract function: report from the Standardisation Sub-committee of the International Continence Society. Neurourol Urodyn 2002;21:167-78.

2. Klausner AP, Vapnek JM. Urinary incontinence in the geriatric population. Mt Sinai J Med 2003;70:54-61.

3. Pang MW, Leung HY, Chan LW, Yip SK. The impact of 
urinary incontinence on quality of life among women in Hong Kong. Hong Kong Med J 2005;11:158-63.

4. Cheung RY, Chan S, Yiu AK, Lee LL, Chung TK. Quality of life in women with urinary incontinence is impaired and comparable to women with chronic diseases. Hong Kong Med J 2012;18:214-20.

5. Aguilar-Navarro S, Navarrete-Reyes AP, Grados-Chavarria BH, Garcia-Lara JM, Amieva H, Avila-Funes JA. The severity of urinary incontinence decreases health-related quality of life among community-dwelling elderly. J Gerontol A Biol Sci Med Sci 2012;67:1266-71.

6. Fan HL, Chan SS, Law TS, Cheung RY, Chung TK. Pelvic floor muscle training improves quality of life of women with urinary incontinence: a prospective study. Aust N Z J Obstet Gynaecol 2013;53:298-304.

7. Dumoulin C, Hay-Smith J. Pelvic floor muscle training versus no treatment, or inactive control treatments, for urinary incontinence in women. Cochrane Database Syst Rev 2010;(1):CD005654.

8. Pereira VS, de Melo MV, Correia GN, Driusso P. Long-term effects of pelvic floor muscle training with vaginal cone in post-menopausal women with urinary incontinence: a randomized controlled trial. Neurourol Urodyn 2013;32:48-52.

9. Wallace SA, Roe B, Williams K, Palmer M. Bladder training for urinary incontinence in adults. Cochrane Database Syst Rev 2004;(1):CD001308.

10. Kim H, Yoshida H, Suzuki T. The effects of multidimensional exercise treatment on community-dwelling elderly Japanese women with stress, urge, and mixed urinary incontinence: a randomized controlled trial. Int J Nurs Stud 2011;48:1165-72.

11. Hay-Smith EJ, Herderschee R, Dumoulin C, Herbison GP. Comparisons of approaches to pelvic floor muscle training for urinary incontinence in women. Cochrane Database Syst Rev 2011;(12):CD009508.

12. Lagro-Janssen TL, Debruyne FM, Smits AJ, van Weel C. Controlled trial of pelvic floor exercises in the treatment of urinary stress incontinence in general practice. Br J Gen Pract 1991;41:445-9.

13. Chiu HF, Lee HC, Chung WS, Kwong PK. Reliability and validity of the Cantonese version of Mini-Mental State Examination: a preliminary study. J Hong Kong Coll Psych 1994;4:25-8.

14. World Medical Association. World Medical Association Declaration of Helsinki: ethical principles for medical research involving human subjects. JAMA 2013;310:21914.

15. Miller JM, Sampselle C, Ashton-Miller J, Hong GR,
DeLancey JO. Clarification and confirmation of the Knack maneuver: the effect of volitional pelvic floor muscle contraction to preempt expected stress incontinence. Int Urogynecol J Pelvic Floor Dysfunct 2008;19:773-82.

16. Kegel AH. Physiologic therapy for urinary stress incontinence. J Am Med Assoc 1951;146:915-7.

17. Tsai $\mathrm{CH}$. The effectiveness of a pelvic floor muscle rehabilitation program in managing urinary tract incontinence among Taiwanese middle age and older women [dissertation]. Pittsburgh: University of Pittsburgh; 2001

18. Castro RA, Arruda RM, Zanetti MR, Santos PD, Sartori MG, Girao MJ. Single-blind, randomized, controlled trial of pelvic floor muscle training, electrical stimulation, vaginal cones, and no active treatment in the management of stress urinary incontinence. Clinics (Sao Paulo) 2008;63:465-72.

19. Zahariou A, Karamouti M, Georgantzis D, Papaioannou P. Are there any UPP changes in women with stress urinary incontinence after pelvic floor muscle exercises? Urol Int 2008;80:270-4.

20. Garber CE, Blissmer B, Deschenes MR, et al. American College of Sports Medicine position stand. Quantity and quality of exercise for developing and maintaining cardiorespiratory, musculoskeletal, and neuromotor fitness in apparently healthy adults: guidance for prescribing exercise. Med Sci Sports Exerc 2011;43:1334-59.

21. Bø K. Pelvic floor muscle strength and response to pelvic floor muscle training for stress urinary incontinence. Neurourol Urodyn 2003;22:654-8.

22. Dannecker C, Wolf V, Raab R, Hepp H, Anthuber C. EMGbiofeedback assisted pelvic floor muscle training is an effective therapy of stress urinary or mixed incontinence: a 7 -year experience with 390 patients. Arch Gynecol Obstet 2005;273:93-7.

23. Herbison GP, Dean N. Weighted vaginal cones for urinary incontinence. Cochrane Database Syst Rev 2013;(7):CD002114.

24. Hay-Smith EJ, Bø Berghmans LC, Hendriks HJ, de Bie RA, van Waalwijk van Doorn ES. Pelvic floor muscle training for urinary incontinence in women. Cochrane Database Syst Rev 2001;(1):CD001407.

25. Hung HC, Chih SY, Lin HH, Tsauo JY. Exercise adherence to pelvic floor muscle strengthening is not a significant predictor of symptom reduction for women with urinary incontinence. Arch Phys Med Rehabil 2012;93:1795-800.

26. Bø K, Hilde G. Does it work in the long term?-A systematic review on pelvic floor muscle training for female stress urinary incontinence. Neurourol Urodyn 2013;32:215-23. 